Document downloaded from:

http://hdl.handle.net/10251/135021

This paper must be cited as:

Moliner, C.; Aguilar, A.; Bosio, B.; Arato, E.; Ribes-Greus, A. (2016). Thermo-oxidative characterisation of the residues from persimmon harvest for its use in energy recovery processes. Fuel Processing Technology. 152:421-429.

https://doi.org/10.1016/j.fuproc.2016.07.008

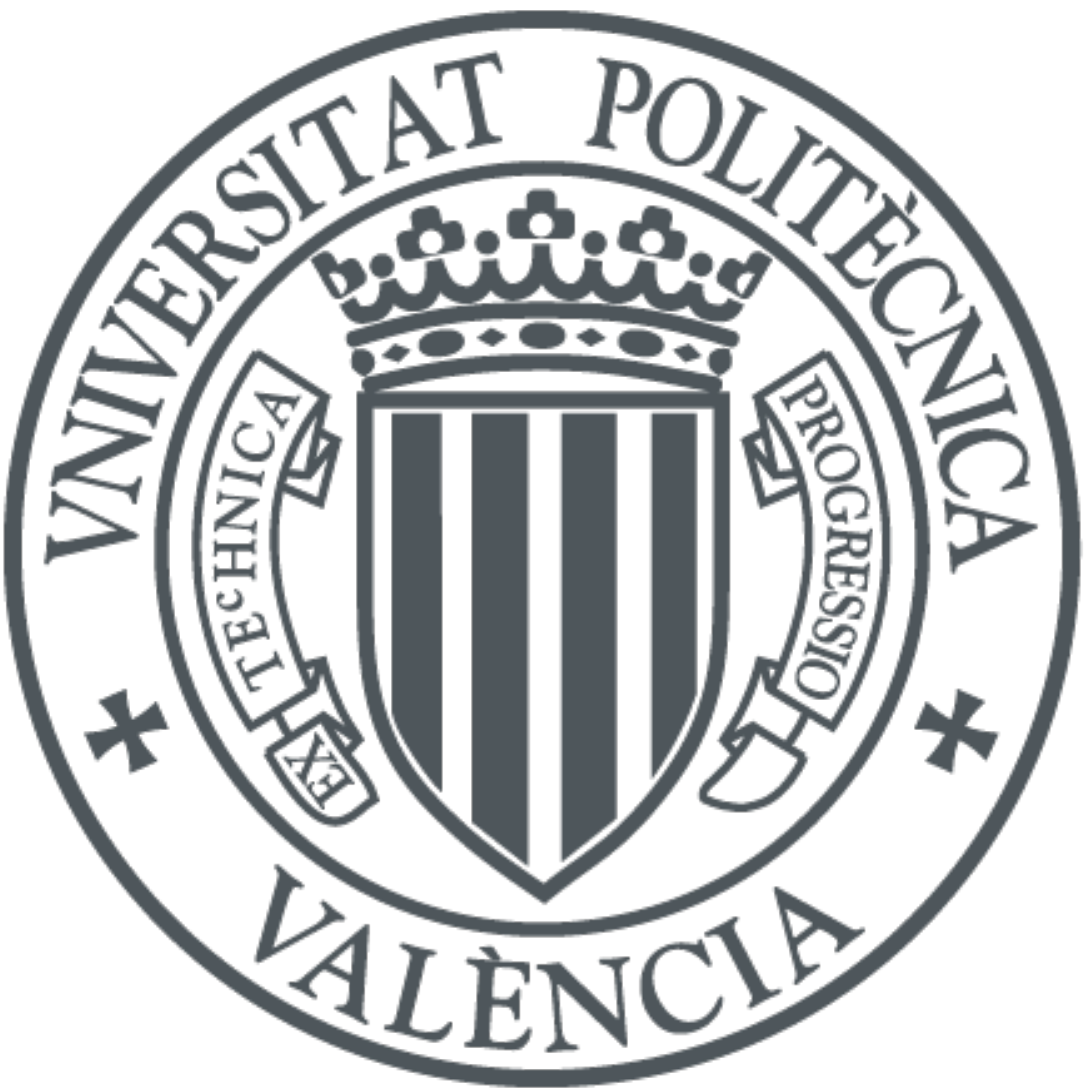

The final publication is available at

https://doi.org/10.1016/j.fuproc.2016.07.008

Copyright Elsevier

Additional Information 


\title{
Thermo-oxidative characterisation of the residues from persimmon harvest for its use in energy recovery processes
}

\author{
C. Molinera ${ }^{\star}$, K. Aguilara , B. Bosio ${ }^{a}$, E. Arato ${ }^{a}$, A. Ribes-Greus ${ }^{b}$
}

This is an open-access version, according to http://www.sherpa.ac.uk/romeo/issn/0378-3820/es/

Full text available at http://www.sciencedirect.com/science/article/pii/S0378382016303095

DOI: http://doi.org/10.1016/i.fuproc.2016.07.008

Please, cite it as:

C. Moliner, K. Aguilar, B. Bosio, E. Arato, A. Ribes-Greus. Thermo-oxidative characterisation of the residues from persimmon harvest for its use in energy recovery processes. Fuel Processing Technology 2016; 152:421-429

a Dipartimento di Ingegneria Civile, Chimica e Ambientale (DICCA),

Università degli Studi di Genova,

Via Opera Pia 15, 16145 Genova (Italy)

${ }^{b}$ Instituto de Tecnologia de Materiales (ITM),

Universitat Politècnica de València,

Camino de Vera s/n, 46022. Valencia (Spain)

*cristina.moliner@edu.unige.it 


\title{
Thermo-oxidative characterisation of the residues from persimmon harvest for its use in energy recovery processes
}

\author{
C. Molinera ${ }^{a}$, K. Aguilara ${ }^{a}$ B. Bosio ${ }^{a}$ E. Arato ${ }^{a}$, A. Ribes-Greus ${ }^{b}$
}

\begin{abstract}
The residues from the harvest of persimmon fruit will be thermally valorised by means of high temperature reactions within a spouted bed reactor. With the aim to obtain valuable information for the design of the device, the thermo-chemical processes were simulated by multi-rate linear non-isothermal Thermogravimetric Analysis (TGA) using $\mathrm{O}_{2}$ as carrier gas. In addition, a set of analyses were carried out using Ar as carrier gas in order to evaluate the influence of the atmosphere (oxidative or inert conditions) on the decomposition of the samples evaluating the reactions of pyrolysis. The release of gases was monitored by Evolved Gas Analysis (EGA) with in-line Fourier Transformed Infrared (FT-IR) analysis. The thermo-chemical reaction was mathematically described through the definition of the main kinetic parameters: activation energy (Ea), pre-exponential factor (In A) and model and order of reaction (n). The so-called kinetic triplet was calculated through the application of a methodology based on complementary iso-conversional methods. These results will be the initial parameters that will help design the Spouted Bed Reactor and it is envisaged that they will be used in computer simulation software to achieve a better understanding of the process to obtain the optimum operational parameters.
\end{abstract}

Keywords: persimmon fruit, energy valorisation, thermo-oxidative decomposition kinetics; evolved-gas analysis 
C. Moliner, K. Aguilar, B. Bosio, E. Arato, A. Ribes-Greus. Thermo-oxidative characterisation of the residues from persimmon harvest for its use in energy recovery processes. Fuel Processing Technology 2016; 152:421-429

\section{List of symbols and abbreviations}

a Degree of conversion

ß Heating rate of thermogravimetric analysis $\left({ }^{\circ} \mathrm{C} / \mathrm{min}\right)$

$\Delta_{\mathrm{mi}}$ - mass loss of the pseudo-components of the biomass (\%)

A Fitting parameter

DTG First-derivative thermogravimetric curve

Ea Apparent activation energy ( $\mathrm{J} / \mathrm{mol})$

$\mathrm{Ea}_{\mathrm{Av}}$ Average apparent activation energy $(\mathrm{J} / \mathrm{mol})$

EGA Evolved Gas Analysis

FT-IR Fourier Transformed Infrared

FWO Flynn-Wall-Ozawa

HHV High heating value $(\mathrm{J} / \mathrm{kg})$

KAS Kissinger-Akahira-Sunose

MP Master plots

$\mathrm{MP}_{\mathrm{f}, \mathrm{g}}$ Differential and integral form of MP

$\mathrm{n}$ Order in kinetic functions

SBR Spouted bed reactor

TB0 Temperature when the heating rate tends to zero $(\mathrm{K})$

TG Thermogravimetric curve

TGA Thermogravimetric Analysis

$\mathrm{T}_{\mathrm{pi}}$ Peak temperatures of the pseudo-components of the biomass $(\mathrm{K})$

VYZ Vyazovkin

$w_{i}$ Fitting parameter

$\mathrm{X}_{\mathrm{ci}}$ Fitting parameter 


\section{Introduction}

The overuse of fossil fuels and the concern over environmental problems have led to an increasing interest on renewable energies worldwide. Biomass and specifically agricultural residues have emerged as suitable feedstock for new energy recovery processes due to its capacity for energy production, with High Heating Values (HHV) around 15MJ/kg [1]. Their high production rates and the necessity of finding them a better and sustainable management have pointed them out as a feasible alternative to traditional fuels.

In this work, the residues of kaki (Diospyros kaki), member of the Ebenaceae family, and especially the variety Rojo Brillante (European Protected Designation of Origin (PDO) label), commonly named persimmon, have been studied for their application in energy recovery processes. According to FAO, the annual production of kaki is more than $4 \cdot 10^{9} \mathrm{~kg}$; the main producers are China $\left(\underline{3.3 \cdot 10^{9} \mathrm{~kg}}\right)$, Republic of Korea $\left(\underline{3.9 \cdot 10^{8} \mathrm{~kg}}\right)$ and Japan $\left(\underline{2.1 \cdot 10^{8} \mathrm{~kg}}\right)$. In Europe, Italy is among

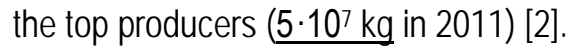

Persimmons adapt perfectly to the Mediterranean climate and prefer clay and well drained soils. The fruit is harvested in the period of September to December. During their cultivation, different types of pruning are carried out: growth, to give the shape of the adult persimmon and fruiting and maintenance, to avoid both the breakage of the branches when the fruit reaches a certain weight. The harvest of persimmon presents some negative environmental aspects related to its residues. Firstly, leaves have a long period of degradation and tend to accumulate on the ground impeding the absorption of water. In addition, the action of the wind can cause obstructions in irrigation channels. Also, persimmon branches are fragile and due to the weight of the fruit, even if all necessary pruning are successfully performed, they tend to break due to wind and rain, producing large crop losses.

The main components of the residues of persimmon are water, lignocellulosic compounds (i.e. hemicellulose, cellulose and lignin) and extractives (i.e. tannins). They also present a great compositional and morphological heterogeneity and thus, an initial study of their thermal properties becomes essential to understand the degradation mechanism of these solid-state reactions prior to its use as energy vectors.

Gasification has been defined as the most convenient technique for thermo-chemical conversions of biomass [3]. A wide range of reactor configurations have been proposed to perform these reactions such as Fixed Bed Reactors, Fluidised Bed Reactors or Spouted Bed Reactors (SBR) among others [4]. However, the industrial scale implementation requires an in-depth understanding of the thermal behaviour of the biomass when submitted to high temperature reactions. Kinetic analysis of heterogeneous reaction systems has become an essential tool for the assessment of the best operational conditions regarding feasibility, design and scale-up of the industrial biomass applications [5].

Valuable parameters for the design and optimisation of the device are obtained by application of Thermogravimetric Analysis (TGA) [6] based on the monitoring of the mass loss of a sample as a function of temperature or time when submitted to a controlled heating programme.

For the stated reasons, the main objective of this work is to study the thermo-oxidative behaviour of the lignocellulosic residues of persimmon through the application of TGA analysis to evaluate their suitability for their use as energy vectors in gasification reactions. In addition, an Evolved Gas Analysis (EGA) has been applied to study the composition of the gas emitted during the process. This kinetic information will be used for the development of a technology based on Spouted Bed Reactors and an energy study in a large-scale gasification process will be further performed with the calculated apparent kinetic model.

\section{Materials and methods}

\subsection{Materials and sample preparation}


Persimmon residues (peel, calyx, pulp, leaves and stems) were collected from the region of Valencia (Spain). The samples were washed, dried in ambient air and milled to produce powders (Figure 1).
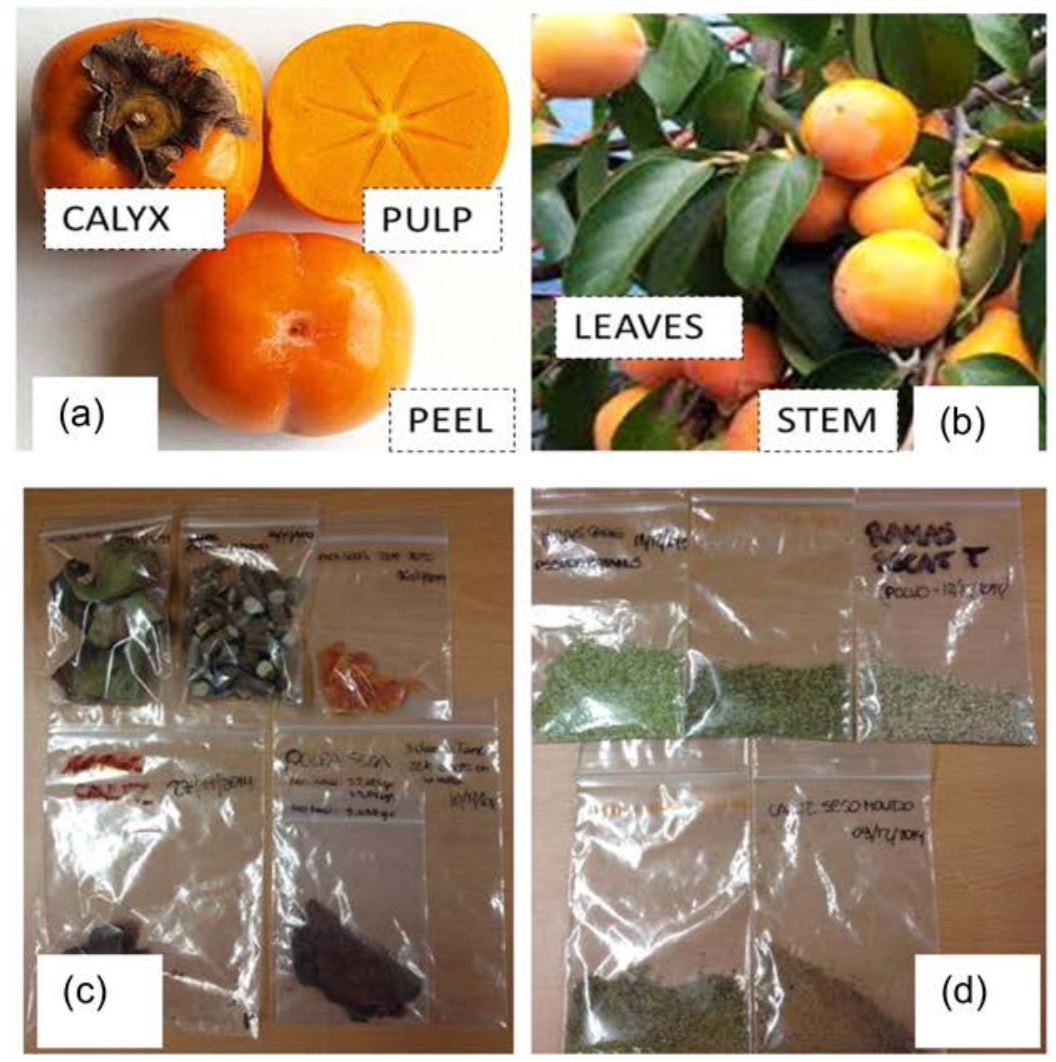

Figure 1. Residues of kaki used in this study: raw material (a) and (b); dried material (c) and milled material (d)

The composition of the materials was obtained according AENOR standard procedures for solid biofuels (UNE-EN 147742:2010: Methods for the determination of moisture content - Oven dry method - Part 2: Total moisture - Simplified method, UNE-EN 15148:2010: Determination of the content of volatile matter and UNE-EN 14775: 2010: Determination of ash content). The distribution of products when biomass is heated under specified conditions (proximate analysis) and the composition of the biomass in base of its constituting elements (ultimate analysis) were calculated.

The preliminary TGA thermograms (as shown in Figure 2) show that peel, pulp and calyx presented high initial moisture contents in their compositions and, as a consequence, their application in energy valorisation processes would require a high energy input to dry the samples. These residues will addressed to a material valorisation for example as source of tannin [7] but it will not be discussed as it is out of the scope of the present work. The thermal characterisation for energy recovery purposes will be focused on the use of leaves and stems. Their compositions are reported in Table 1 . The size of particle was approximately $3 \mathrm{~mm}( \pm 0.5)$ in all cases. The higher heating value was obtained by application of the relation by Channiwala and Parikh [8]:

$$
H H V(M J / k g)=0.3491 \cdot \% C+1.1783 \cdot \% H+0.1005 \cdot \% S-0.1034 \cdot \% O-0.0151 \cdot \% N-0.0211 \cdot \% A
$$

Where $\mathrm{C}, \mathrm{H}, \mathrm{S}, \mathrm{O}, \mathrm{N}$ and $\mathrm{A}$ are the content (\%w/w) of carbon, hydrogen, sulphur, oxygen, nitrogen and ash in the samples. The calculated HHV was $13.1 \mathrm{MJ} / \mathrm{kg}$ (leaves) and $17.3 \mathrm{MJ} / \mathrm{kg}$ (stems) indicating the suitability of the residues of persimmon fruit for thermo-chemical conversion processes. 
Table 1. Composition of leaves and stems of persimmon

\begin{tabular}{|c|c|c|c|c|c|c|c|c|c|}
\hline & \multicolumn{5}{|c|}{ Ultimate analysis (\%w/w) } & \multicolumn{4}{|c|}{ Proximate analysis (\% w/w) } \\
\hline & C & $\mathrm{H}$ & 0 & $\mathrm{~N}$ & S & $\begin{array}{c}\text { Moisture } \\
\text { (M) }\end{array}$ & $\begin{array}{c}\text { Volatile } \\
\text { Matter } \\
\text { (VM) }\end{array}$ & $\begin{array}{c}\text { Fixed } \\
\text { Carbon } \\
(\mathrm{FC})\end{array}$ & Ash \\
\hline Leaves & $\begin{array}{c}38.1 \\
( \pm 2.6)\end{array}$ & $\begin{array}{c}4.8 \\
( \pm 0.5)\end{array}$ & $\begin{array}{c}56.2 \\
( \pm 3.3)\end{array}$ & $\begin{array}{c}0.8 \\
( \pm 0.2)\end{array}$ & $\begin{array}{c}0.1 \\
( \pm 0.06)\end{array}$ & $\begin{array}{c}9.3 \\
( \pm 0.8)\end{array}$ & $\begin{array}{c}76.3 \\
( \pm 7.1)\end{array}$ & $\begin{array}{c}1.8 \\
( \pm 2.0)\end{array}$ & $\begin{array}{c}12.6 \\
( \pm 2.0)\end{array}$ \\
\hline Stems & $\begin{array}{c}45.8 \\
( \pm 1.7)\end{array}$ & $\begin{array}{c}5.3 \\
( \pm 0.1)\end{array}$ & $\begin{array}{c}48.0 \\
( \pm 1.6)\end{array}$ & $\begin{array}{c}0.9 \\
( \pm 0.03)\end{array}$ & 0 & $\begin{array}{c}9.8 \\
( \pm 0.5)\end{array}$ & $\begin{array}{c}82.8 \\
( \pm 4.1)\end{array}$ & $\begin{array}{c}2.1 \\
( \pm 0.6)\end{array}$ & $\begin{array}{c}5.3 \\
( \pm 4.2)\end{array}$ \\
\hline
\end{tabular}

\subsection{Thermogravimetric analyses}

Multi-rate non-isothermal Thermogravimetric Analysis (TGA) was carried out in a Mettler Toledo TGA/SDTA 851 (Columbus, $\mathrm{OH}$ ). Samples weighing about $5 \mathrm{mg}$ were heated in an alumina holder with capacity for $70 \mu \mathrm{l}$. Experiments were performed from $25^{\circ} \mathrm{C}$ to $800^{\circ} \mathrm{C}$ at different heating rates $\left(B=5,10,15,20,25,30^{\circ} \mathrm{C} / \mathrm{min}\right.$ ) under a constant flow of 50 $\mathrm{ml} / \mathrm{min}$ of gas of analysis. All samples were analysed under oxidant $\left(\mathrm{O}_{2}\right)$ atmosphere to characterise the thermo-oxidative process and under inert conditions ( $\mathrm{Ar}$ ) to evaluate the effect of the atmosphere of work on the process through the assessment of the reactions of pyrolysis. Assessment was performed with the aid of the software Stare 9.10 from Mettler Toledo. All the experiments were repeated three times to ensure their reproducibility and the average values were considered as representative values.

\subsection{Evolved Gas Analysis}

Evolved Gas Analysis (EGA) was applied for the analysis of fumes released by combustion by means of coupled TGA/FTIR experiments. The temperature range of study was $25-600^{\circ} \mathrm{C}$ with a heating rate equal to $1^{\circ} \mathrm{C} / \mathrm{min}$. Sample weighting $40 \mathrm{mg}$ aprox. were heated in an alumina holder with capacity for $900 \mu \mathrm{L}$. The flow rate of oxygen was fixed to $25 \mathrm{~mL} / \mathrm{min}$. FT-IR gas-phase spectra were collected by a previously calibrated Thermo Nicolet 5700 FT-IR Spectrometer (MA, USA) in the range $4000-600 \mathrm{~cm}^{-1}$ of wave number at a resolution of $4 \mathrm{~cm}^{-1}$. Both transfer line and gas cell were kept at $250^{\circ} \mathrm{C}$ to prevent gas condensation. The spectra were analysed with the aid of software OMNIC 7.0.

\section{Results and discussion}

\subsection{Thermo-oxidative decomposition profiles}

The thermal performance of the different materials was initially addressed. The thermogravimetric curves (TG) and their first derivative curves (DTG) were obtained for each sample at all heating rates $\beta$ and compared between them. Figure 2 represents the TG (a) and DTG (b) curves of leaves and stems at $\beta=10^{\circ} \mathrm{C} /$ min under oxidative conditions. In addition, the study of the use of the residual fruits (peel, pulp and calyx) after the harvest was also evaluated but they were not found to be suitable for energy recovery systems and for that reason, the thermal characterisation will be focused on the use of leaves and stems for energy purposes. 

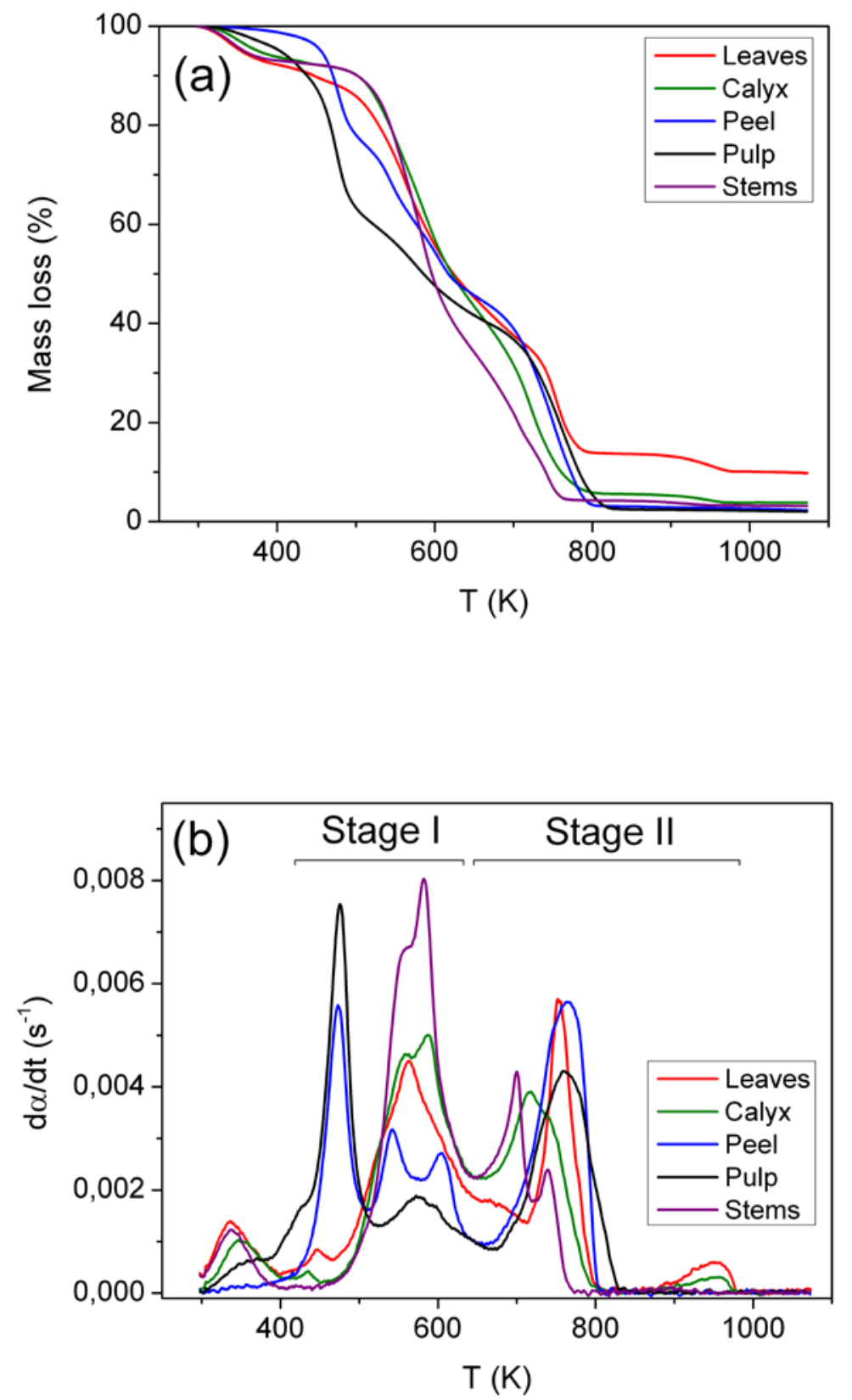

Figure 2. TG (a) and DTG (b) curves of persimmon residues at $\beta=10^{\circ} \mathrm{C} / \mathrm{min}$

The thermograms reveal two well-differentiated stages in all cases: firstly, the pyrolysis and heterogeneous oxidation reactions (Stage I) and, secondly, a broad region attributed to a further combustion of char (Stage II) [9].

The highest weight loss of the thermo-oxidative process occurred in the range 400-800K as shown in Figure 2. Below this temperature, only moisture and extractives evolved. A small peak at 440K was found for the leaves of persimmon. This peak was clearly observed for the pulp and peel and was assigned to the degradation of tannins present in the fruit, also in accordance to previous works.[7]. 
The main decomposition stage for both leaves and stems was attributed to the degradation of the lignocellulosic fraction of biomass. Hemicellulose was the least stable component followed by cellulose, which presented a narrow peak at $600 \mathrm{~K}$. Lignin had a wide range of decomposition temperatures, resulting in high char yields, which burnt at the highest temperatures (around 773K). Above 900K, a minor weight loss for leaves was observed, mainly related to the further combustion of the produced chars as a result of the high temperatures achieved. Finally, an averaged quantity of 15 and $5 \%$ of ash (in leaves and stems respectively) was obtained as the final residue of the reaction.

Both TG and DTG show that the decomposition rate is highly related to composition of biomass. It is more than evident that the overall decomposition process should be taken as the sum of several pseudo-components (represented by each of the obtained peaks). Moreover, the existence of shoulders evidenced the degradation of more than one component in that range of temperatures. For this reason, a deconvolution process was carried out in order to individually characterise the thermo-oxidative behaviour of each pseudo-component. The deconvoluted curves of leaves and stems of persimmon and their fitting on the original data are represented in Figure 3 at different heating rates. All the curves were fitted to a Gaussian curve according to (2):

$$
y=\sum_{i=1} A_{i} \cdot \exp \left(-\mathbf{U} \cdot \mathrm{b} \cdot \frac{\ldots}{w_{i}^{2}}\right)
$$

with $A, x_{c i}$ and $w_{i}$ being the fitting parameters and $n$ the total number of pseudo-components
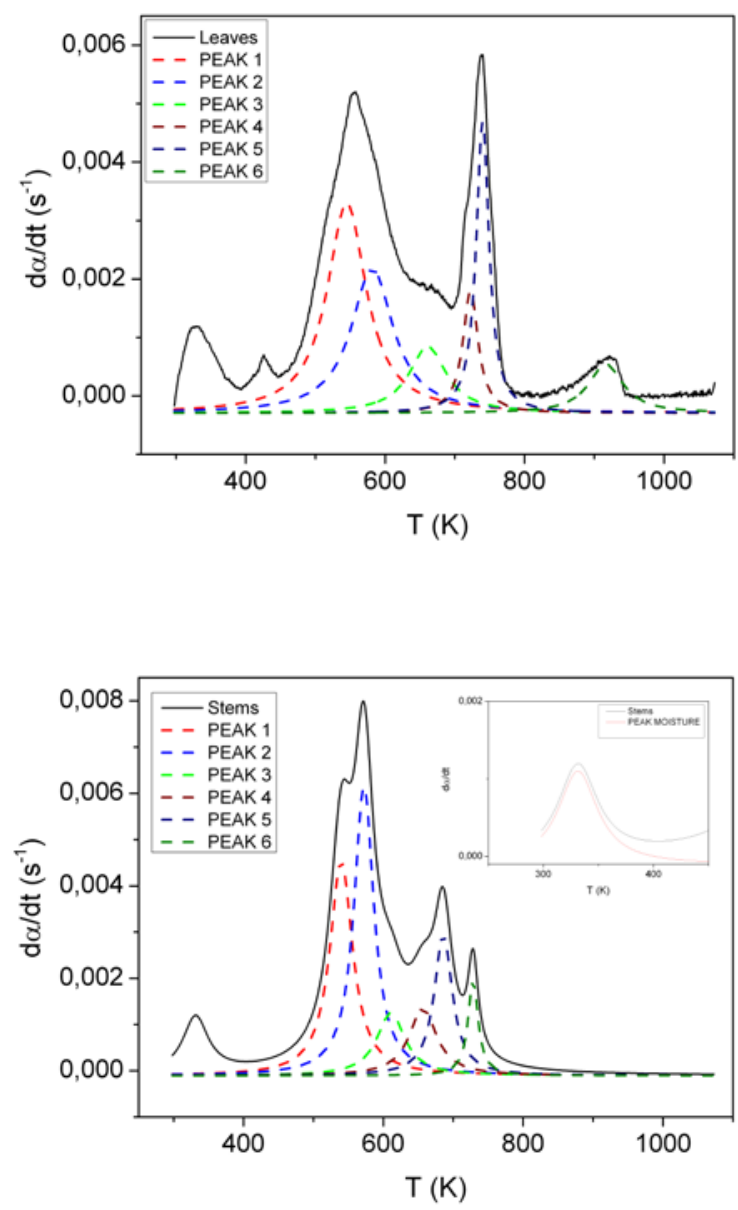

Figure 3. Results of deconvolution procedure 
All the temperatures of decomposition ( $T_{\mathrm{pi}}$, i=pseudo-components) and their associated mass losses $\left(\Delta_{\mathrm{mi}}\right)$ and maximum rates of decomposition $\left((d \alpha / d t)_{i}\right)$, are presented in Table 2 for both leaves and stems at $\beta=10^{\circ} \mathrm{C} / \mathrm{min}$. The conversion degree $\alpha$ is defined as $\alpha=\left(m_{0}-m_{i}\right) /\left(m_{0}-m_{\infty}\right)$, where $m$ is the mass with the subscripts 0 , i and $\infty$ standing for initial, instant and final respectively.

Table 2. the temperatures of decomposition ( $T_{\mathrm{p} i}$ i $\mathrm{i}=$ pseudo-components) and their associated mass losses $\left(\Delta_{\mathrm{mi}}\right)$ and maximum rates of decomposition $(d \alpha / d t)_{i}$

\begin{tabular}{|c|c|c|c|c|c|c|c|c|c|c|c|c|}
\hline & $\operatorname{Teten}_{(K)}$ & (2) $(\%)$ & $\operatorname{Teses}(K)$ & $8(\%)$ & Tewe $(K)$ & \& (\%) & $T_{\text {texto }}(\mathrm{K})$ & e(\%) & $\operatorname{Tasses}_{(K)}$ & \& (\%) & Teste $(K)$ & \& (\%) \\
\hline & \multicolumn{2}{|c|}{ Hemicellulose } & \multicolumn{2}{|l|}{ Cellulose } & \multicolumn{2}{|l|}{ Lignin } & \multicolumn{2}{|c|}{ Char Hemicellulose } & \multicolumn{2}{|c|}{ Char Cellulose } & \multicolumn{2}{|l|}{ Char Lignin } \\
\hline Leaves & 525 & \pm 0.0 & 564 & \pm 0.1 & 605 & \pm 0.2 & $6 / 9$ & \pm 0.3 & 742 & \pm 0.4 & 762 & \pm 1.0 \\
\hline \multirow[t]{2}{*}{ Stems } & 551 & \pm 0.1 & 584 & \pm 0.3 & 620 & \pm 0.2 & 671 & \pm 0.5 & 703 & \pm 0.6 & 743 & \pm 0.3 \\
\hline & 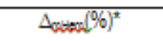 & \&(\%) & $\Delta_{\cos \alpha}(\%)^{x}$ & e (\%) & $\Delta_{\text {cwod }}(\%)^{*}$ & \& (\%) & $\Delta_{0 c \cos (1 \%)^{*}}$ & e. (\%) & $\Delta_{\cos s e}(\%)^{*}$ & $\mathrm{e}(\%)$ & 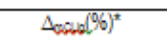 & e $(\%)$ \\
\hline Leaves & 16 & \pm 8.4 & 17 & \pm 8.3 & 11 & \pm 3.2 & 8 & \pm 16.0 & 11 & \pm 2.0 & 37 & \pm 9.7 \\
\hline \multirow[t]{2}{*}{ Stems } & 30 & \pm 4.2 & 28 & \pm 5.2 & 9 & \pm 3.3 & 10 & \pm 11.0 & 14 & \pm 13.3 & 9 & \pm 13.6 \\
\hline & $(\mathrm{da} / \mathrm{dt})=00\left(\mathrm{sec}^{-1}\right)$ & e(\%) & $(\mathrm{da} / \mathrm{dt})_{s e}\left(\mathrm{sec}^{-1}\right)$ & e (\%) & $\left(\mathrm{do} / \mathrm{dt}_{42}\left(\mathrm{sec}^{-1}\right)\right.$ & $2(\%)$ & $(\mathrm{da} / \mathrm{dt})_{\mathrm{s}+20}\left(\mathrm{sec}^{-1}\right)$ & e (\%) & $(\mathrm{da} / \mathrm{dt})$ bese $\left(\mathrm{sec}^{-1}\right)$ & $8(\%)$ & $(\mathrm{do} / \mathrm{dt})_{\operatorname{sid}}\left(\mathrm{sec}^{-1}\right)$ & $\mathrm{e}(\%)$ \\
\hline Leaves & 0.0011 & \pm 11.8 & 0.0034 & \pm 5.3 & 0.0014 & $\pm / .1$ & 0.0008 & \pm 15.1 & 0.0047 & \pm 8.1 & 0.0018 & \pm 9.6 \\
\hline Stems & 0.0015 & \pm 8.8 & 0.0053 & \pm 7.8 & 0.0011 & \pm 7.2 & 0.0013 & \pm 14.5 & 0.0026 & \pm 11.1 & 0.0023 & \pm 15.3 \\
\hline
\end{tabular}

According to the calculated values, the percentage of each lignocellulosic compound in the samples was approximately $24 \%( \pm 15), 28 \%( \pm 15)$ and $48 \%( \pm 20)$ for leaves and $40 \%( \pm 6), 42 \%( \pm 7)$ and $18 \%( \pm 7)$ for stems. These results are in line with previous studies [10] where both hemicellulose and cellulose were found in higher percentage in stems than in leaves for the case of different types of biomass. Also, a higher quantity of char was observed in leaves respect to that of stems, as it is also the case of the residue of persimmon.

In order to study the reactions of pyrolysis of the samples, stems and leaves were submitted to a new set of themogravimetric experiments using Ar as carrier gas at a fixed $\beta=10^{\circ} \mathrm{C} / \mathrm{min}$ (Figure 4). As expected, the use of an inert atmosphere resulted in a shift to higher temperatures for the characteristic peaks as a result of a less reactive environment. Moreover, the peaks related to the combustion of char (Stage II) were more evident and sharper in oxidative conditions respect to those with an inert carrier gas. It was thus confirmed the influence of the atmosphere of work on the decomposition processes of both leaves and stems, especially on the stage corresponding to the combustion of char, where the high concentration of $\mathrm{O}_{2}$ at high temperatures promotes its further interaction with the products of previous stages [8]. 


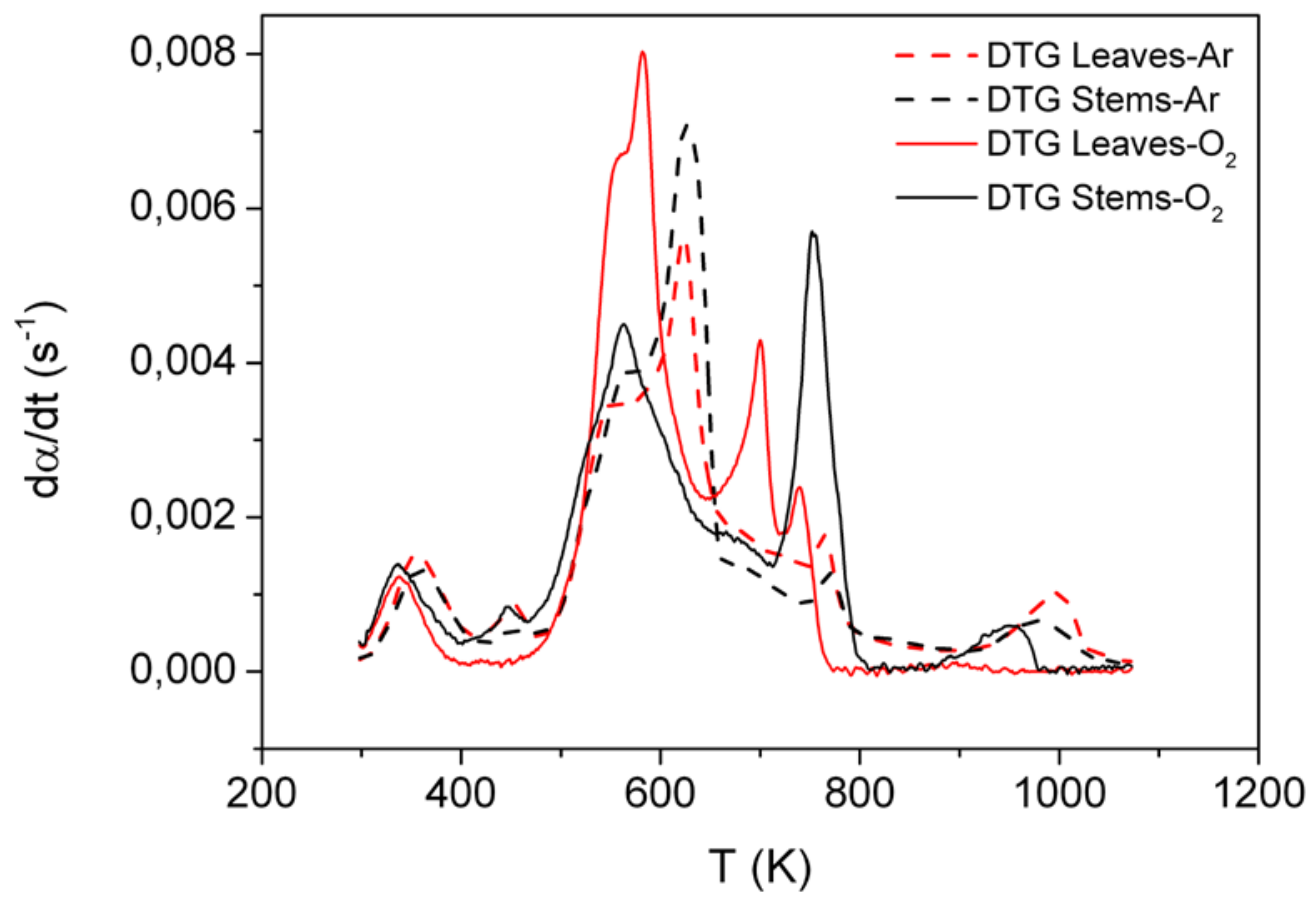

Figure 4. DTG of leaves (red lines) and stems (black lines) at $10^{\circ} \mathrm{C} /$ min with $\mathrm{Ar}$ (pointed) and $\mathrm{O}_{2}$ (line)

\subsection{Thermo-oxidative stability under any linear heating rate}

Lignocellulosic biomass is commonly stable until $425 \mathrm{~K}$. Minor mass losses associated to the removal of free moisture and hydrolysis of some extractives occur at low temperatures [6]. Furthermore, the degradation of the principal constituents can be categorised into discrete temperature ranges. This enables the control of the decomposition process at any temperature and provides information to elucidate what products can be mainly obtained according to the component being preferentially decomposed.

With this purpose, the range of stability of leaves and stems of persimmon under reactive atmosphere was evaluated. The prediction of the minimum decomposition temperatures for each of the pseudo-components in the samples permitted to evaluate the trigger of decomposition and the most suitable temperatures of work according to the desired preferential products.

Figure 5 shows the evolution of the previously calculated characteristic temperatures ( $T_{\mathrm{pi}}, \mathrm{i}=$ pseudo-components) of leaves (a) and stems (b) at all heating rates under reactive environment and their associated error values in form of error bars. As it was expected, faster heating rates led to higher characteristic temperatures due to heat transfer limitations [6]. In order to avoid this influence of linear heating procedures in the evaluation of the characteristic temperatures (i.e. help functionalise the thermal stability under combustion processes), the temperature obtained when the heating rate tends to zero (TB0) was calculated according to a previously developed methodology [11, 12]. 

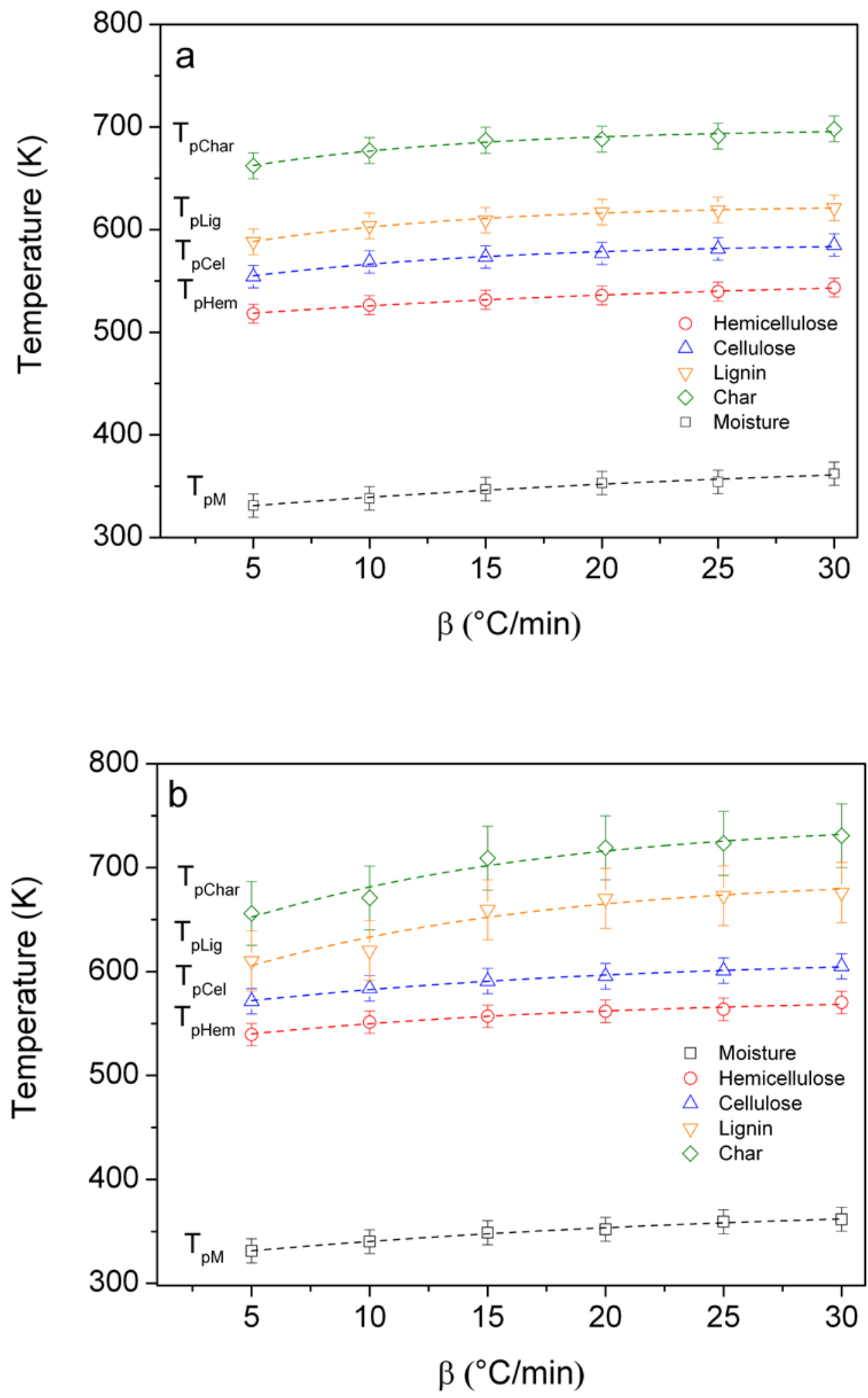

Figure 5. Evolution of characteristic temperatures of decomposition with the heating rate for leaves (a) and stems (b) 
That way, TB0 was used to evaluate the thermo-oxidative stability of all samples at each decomposition stage: TB0M permitted to evaluate the minimum temperature required for the removal of moisture; $\mathrm{TB}_{\mathrm{H}}, \mathrm{TB}_{\mathrm{C}}$ and $\mathrm{TBO}_{\mathrm{L}}$ were used to evaluate the trigger of decomposition of each component (i.e. hemicellulose, cellulose and lignin respectively) and $\mathrm{TBO}_{\text {char }}$ provided the temperature to start the combustion of char. Table 3 presents the fitting parameters, the fitting regression coefficient and the value of TBO for each decomposition stage.

Table 3. Fitting parameters and TBO for each decomposition process for stems and leaves

\begin{tabular}{|c|c|c|c|c|c|c|c|c|}
\hline Stems & $a^{*}$ & e (\%) & $b^{*}$ & e (\%) & $k^{*}$ & e (\%) & $\mathrm{R}^{2}$ & TB0 STEMs (K) \\
\hline Moisture & 375.1 & \pm 7.54 & 0.22 & \pm 0.030 & 0.05 & \pm 0.001 & 0.987 & 375 \\
\hline Hemicellulose & 575.2 & \pm 5.98 & 0.22 & \pm 0.040 & 0.07 & \pm 0.002 & 0.971 & 575 \\
\hline Cellulose & 613.5 & \pm 4.22 & 0.10 & \pm 0.005 & 0.06 & \pm 0.001 & 0.992 & 614 \\
\hline Lignin & 689.9 & \pm 21.39 & 0.09 & \pm 0.008 & 0.08 & \pm 0.004 & 0.888 & 690 \\
\hline Char & 744.6 & \pm 19.10 & 0.17 & \pm 0.020 & 0.08 & \pm 0.003 & 0.932 & 745 \\
\hline Leaves & $a^{*}$ & e (\%) & $b^{*}$ & e (\%) & $k^{*}$ & e (\%) & $\mathrm{R}^{2}$ & TB0 $_{\text {LEAVES }}(\mathrm{K})$ \\
\hline Moisture & 380.0 & \pm 19.19 & 0.09 & \pm 0.011 & 0.04 & \pm 0.002 & 0.968 & 380 \\
\hline Hemicellulose & 554.5 & \pm 4.44 & 0.10 & \pm 0.007 & 0.05 & \pm 0.001 & 0.995 & 554 \\
\hline Cellulose & 586.9 & \pm 3.69 & 0.09 & \pm 0.009 & 0.09 & \pm 0.002 & 0.969 & 587 \\
\hline Lignin & 623.8 & \pm 2.23 & 0.09 & \pm 0.006 & 0.10 & \pm 0.002 & 0.987 & 624 \\
\hline Char & 698.3 & \pm 4.39 & 0.18 & \pm 0.047 & 0.10 & \pm 0.003 & 0.953 & 698 \\
\hline
\end{tabular}

\subsection{Decomposition kinetics}

The kinetics of decomposition is an essential parameter for the correct design of a device for thermal conversion processes. They define the start-up conditions to be applied to the system to initiate the thermal process and also provide information on the reaction times required to complete the thermo-chemical conversions. Figure 6 shows the procedure that was carried out to calculate the kinetic triplet that describes the combustion reactions of leaves and stems of persimmon. 


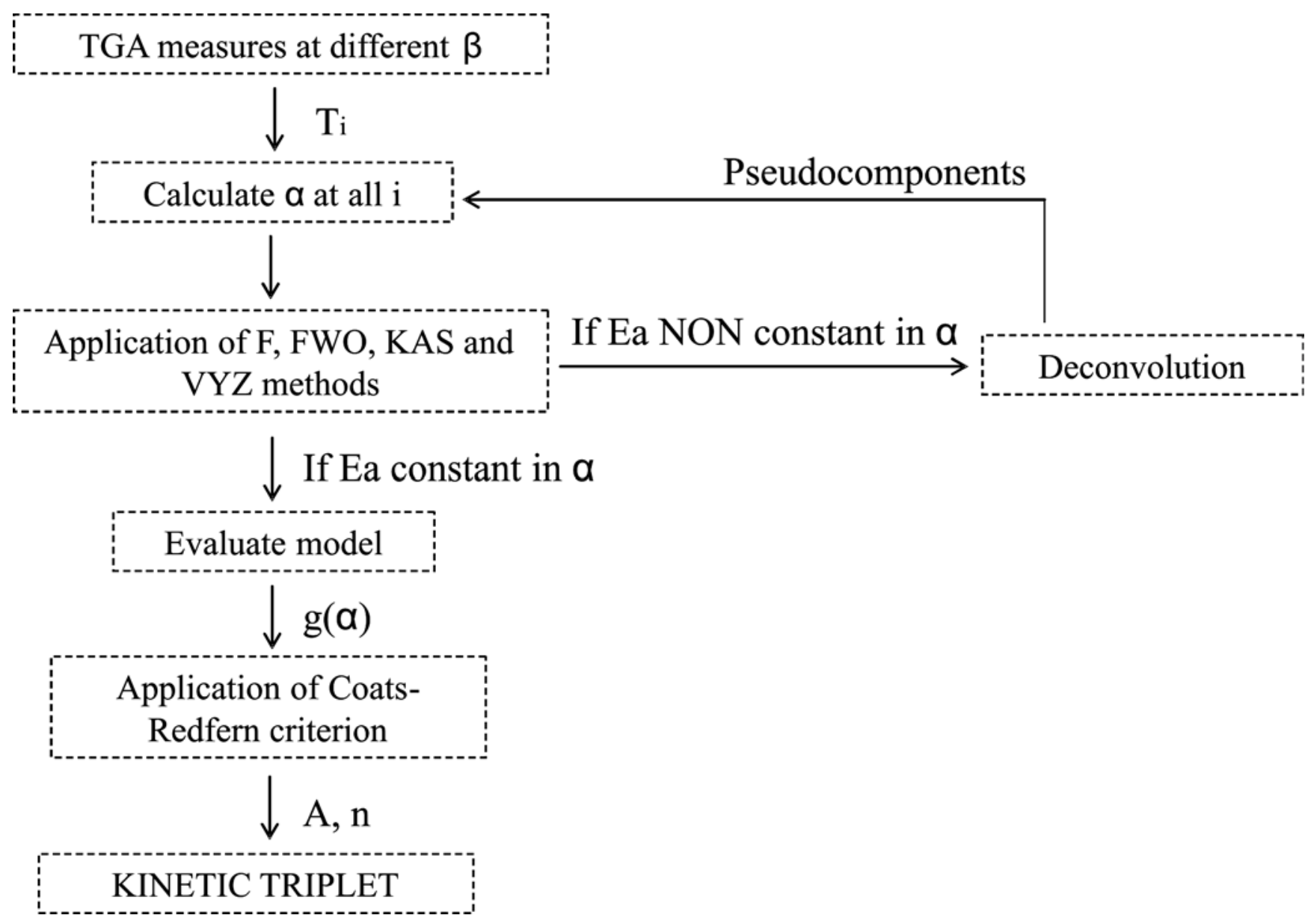

Figure 6. Procedure for the calculation of the kinetic triplet

\subsubsection{Apparent activation energies}

The iso-conversional methods Flynn-Wall-Ozawa (FWO) [13], Kissinger-Akahira-Sunose (KAS) [14] and Vyazovkin (VYZ) [15] were applied to evaluate the dependence of the apparent activation energy (Ea) with the conversion degree $\alpha$. The three mentioned methods were selected in order to calculate the Ea according to different approaches: linear integral methods (FWO and KAS) and non linear integral methods (VYZ) using the approximation of Senum-Yang truncated to the fifth term [16]. VYZ provides the most accurate results as the calculations are based on minimisation methods. FWO and KAS were also applied to confirm and complement the results. The iso-conversional methods were applied to each of the deconvoluted curves (previously calculated in Section 3.1) to obtain the kinetic function describing the reactions for each component and their associated stage of combustion of char.

The temperature range for all the kinetic studies was considered above $T \sim 425 \mathrm{~K}$ as, at temperatures below this value, only moisture and absorbed water was removed and its kinetics did not exhibit differences with the change of heating rates. The calculated values corresponded to the range of conversion $\alpha=0.2-0.8$ where the main reactions took place.

Figure 7a presents the application of FWO method for hemicellulose in stems. The well-defined straight lines obtained show that the FWO method provides a reasonable fit. The slope of the lines defined the activation energy for each conversion degree. All the components (hemicellulose, cellulose, lignin and their corresponding chars) presented regression coefficient values above 0.95 . 

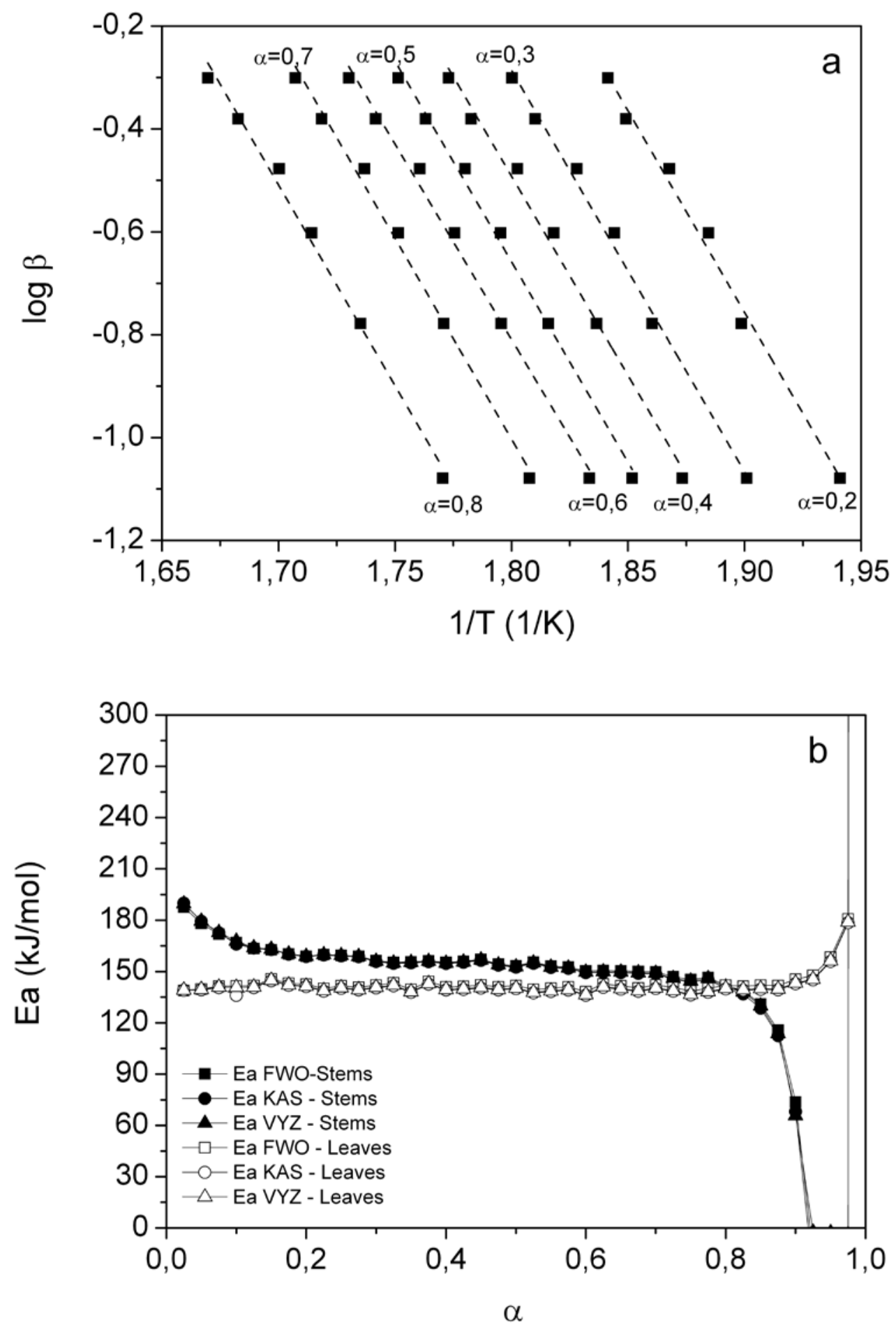

Figure 7. Application of FWO method for hemicellulose in stems (a); Evolution of apparent activation energy (Ea) with the conversion degree evaluated by FWO, KAS and VYZ methods for hemicellulose in stems (full symbols) and leaves (empty symbols) 
Figure $7 \mathrm{~b}$ shows the results of the evaluation of the apparent activation energy (Ea) of the component hemicellulose in stems (full symbol) and leaves (empty symbol) with the variation of the conversion degree obtained by FWO, KAS and VYZ methods. The calculated Ea shows a good agreement between the three methods and a constant trend in the range of study. The same behaviour was observed for all components for both leaves and stems but is not presented for the sake of conciseness.

Table 4 gathers the values of the averaged calculated apparent activation energy (Ea) in the range of study for each pseudo-component by application of the previously mentioned methods. The error values correspond to the difference among the three repetitions performed for all samples to ensure the reproducibility of the experiments. Additionally, Table 5 presents the averaged values of activation energy for each component for leaves and stems where, in this case, the error values are referred to the variation among the results obtained by the application of the three different methods.

Table 4. Apparent activation energy values (in $\mathrm{kJ} / \mathrm{mol}$ ) obtained with the different iso-conversional methods (range $\alpha=0.2-0.8)$

\begin{tabular}{l|llllll|lllllll}
\hline & \multicolumn{3}{|l}{ Leaves } & \multicolumn{1}{l|}{ Stems } & & & & & \\
& Eafwo & $\mathrm{e}(\%)$ & EakAs & $\mathrm{e}(\%)$ & Eavyz & $\mathrm{e}(\%)$ & Eafwo & $\mathrm{e}(\%)$ & EakAs & $\mathrm{e}(\%)$ & Eavyz & e (\%) \\
\hline Hemicellulose & 153 & \pm 9.9 & 152 & \pm 13.4 & 153 & \pm 7.7 & 144 & \pm 9.5 & 142 & \pm 11.7 & 140 & \pm 2.3 \\
Cellulose & 164 & \pm 9.3 & 163 & \pm 12.4 & 164 & \pm 8.5 & 147 & \pm 8.9 & 144 & \pm 10.6 & 145 & \pm 9.9 \\
Lignin & 59 & \pm 6.7 & 50 & \pm 12.0 & 52 & \pm 7.7 & 73 & \pm 7.7 & 66 & \pm 2.9 & 67 & \pm 7.3 \\
Char Hem & 125 & \pm 6.8 & 119 & \pm 3.5 & 119 & \pm 1.1 & 78 & \pm 7.1 & 71 & \pm 3.1 & 72 & \pm 1.5 \\
Char Cel & 130 & \pm 6.6 & 124 & \pm 3.6 & 124 & \pm 5.6 & 80 & \pm 6.7 & 72 & \pm 3.9 & 73 & \pm 4.8 \\
Char Lig & 149 & \pm 5.3 & 141 & \pm 1.8 & 141 & \pm 3.6 & 124 & \pm 6.7 & 118 & \pm 3.4 & 118 & \pm 6.3 \\
\hline
\end{tabular}

Table 5. Averaged activation energy values (in $\mathrm{kJ} / \mathrm{mol}$ ) (range $\alpha=0.2-0.8$ )

\begin{tabular}{l|ll|ll} 
& \multicolumn{2}{|c|}{ Leaves } & \multicolumn{2}{c}{ Stems } \\
\hline & Ea & e (\%) & Ea & e (\%) \\
\hline Hemicellulose & 153 & \pm 0.21 & 142 & \pm 0.94 \\
Cellulose & 164 & \pm 0.20 & 145 & \pm 0.93 \\
Lignin & 54 & \pm 6.80 & 69 & \pm 4.30 \\
Char Hem & 121 & \pm 2.20 & 74 & \pm 4.00 \\
Char Cel & 126 & \pm 2.11 & 75 & \pm 4.50 \\
Char Lig & 144 & \pm 1.70 & 120 & \pm 2.20
\end{tabular}


The obtained results are comparable to those obtained in previous works for the combustion of sugarcane bagasse [17] and cardoon stems and leaves [18] in which the calculated values ranged from 50-180 kJ/mol (hemicellulose), 72-256 $\mathrm{kJ} / \mathrm{mol}$ (cellulose) and 21-77 kJ/mol (lignin).

\subsubsection{Evaluation of the pre-exponential factor and the order of reaction}

Iso-conversional methods allow estimating the activation energy of a reaction without previous assumptions on the reaction model. In order to obtain the complete kinetic triplet, the pre-exponential factor and the model and exact order of reaction were calculated. An initial assessment of the mechanism of reaction was performed with the aid of the Master Plots (MP) [19]. Figure 8 shows the MP of hemicellulose (a) and hemicellulose char (b) in stems at $10^{\circ} \mathrm{C} / \mathrm{min}$. By comparison with the theoretical curves (Kinetic Models: $D_{n}$ : diffusion controlled, red lines, $A_{n}$ : nucleation and growth, blue lines, $F_{n}$ : $n$-order reaction, green lines, $R_{n}$ : reaction controlled, black lines), the model which best fitted the experimental curves (purple line) was obtained. As shown in the figure, the resulting prevailing model was $F_{n}$ to describe the first stage of decomposition (i.e. pyrolysis and heterogeneous reactions of hemicellulose, cellulose and lignin) and it changed to an $A_{n}$ model which was found more suitable to describe the combustion of all the produced chars. According to the models, the initial stage of decomposition would be produced as a result of a reaction which rate is proportional to the fraction of remaining reactant. On the contrary, the model based on nucleation obtained for the combustion of char could be the consequence of the creation of different reaction sites in the previous stages of reaction, with a more similar mechanism of reaction to those found in heterogeneous reactions [20].
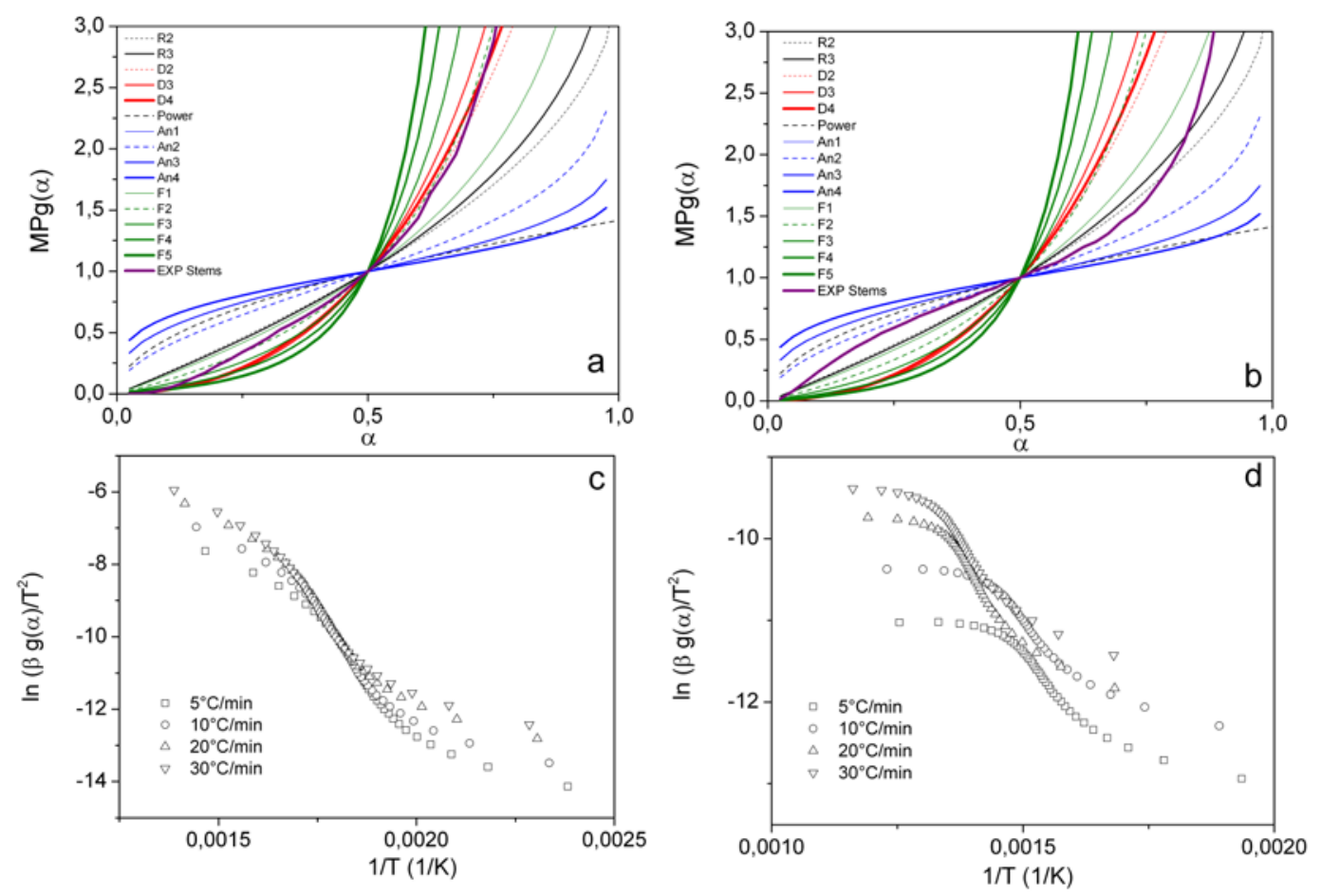

Figure 8. Kinetic Models: $D_{n}$ : diffusion controlled, red lines, $A_{n}$ : nucleation and growth, blue lines, $F_{n}$ : $n$-order reaction, green lines, $R_{n}$ : reaction controlled, black lines), experimental curves (purple line) for hemicellulose (a) and hemicellulose char (b) in stems; application of the Perez-Maqueda et al criterion for the simplified kinetic triplet for hemicellulose (c) and hemicellulose char (d) in stems 
Finally, the application of the Coats-Redfern equation (3) [21] permitted to calculate the pre-exponential factor and the exact order of reaction according to the previously obtained mechanism. According to this criterion, the points $[\mathrm{x}, \mathrm{y}]$ should lie on the same straight line to all heating rates. Figure 8 shows an example of the application of this criterion for hemicellulose (c) and hemicellulose char (d) in stems where it is observed that all points in the range of study laid on the same line.

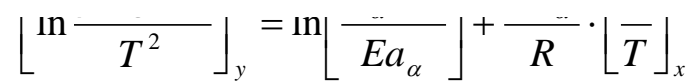

with $g(\alpha)$ being the integral form of the model previously obtained [19].

As a result of the calculations performed, the pre-exponential factor $(\ln A)$ was calculated from the intercept of the line with the axis. The order of reaction was firstly calculated with the aid of MP (n-MP) and, once the model was fixed, $n$ was analytically recalculated ( $n$-analytical) showing a remarkable good agreement between the two results. The results of all the parameters are presented in Table 6.

Table 6. Kinetics parameters for leaves and stems of persimmon

\begin{tabular}{l|cccc|lllll}
\hline Leaves & In A & e (\%) & n-MP & n-analytical & Stems & In A & e (\%) & n-MP & n-analytical \\
\hline Hemicellulose & 34.1 & 10.2 & F1-F2 & 1.42 & Hemicellulose & 29.8 & 3.3 & F2 & 2.05 \\
Cellulose & 35.9 & 1.7 & F4-F5 & 4.37 & Cellulose & 29.2 & 14.6 & F1-F2 & 1.80 \\
Lignin & 8.49 & 9.7 & F1 & 1.02 & Lignin & 11.4 & 9.5 & F1 & 0.61 \\
Char Hem & 18.2 & 11.2 & A2 & 1.89 \\
Char Cel & 18.3 & 19.0 & A2-A3 & 2.78 & Char Hem & 11.0 & 13.9 & A1-A2 & 1.79 \\
Char Lig & 16.1 & 3.73 & A1-A2 & 1.31 & Char Cel & 10.3 & 22.2 & A2-A4 & 3.12 \\
\hline
\end{tabular}

\subsection{Evolved Gas Analysis}

The emission of gases during the thermo-oxidative decomposition of the biomass was monitored by in-line FT-IR analysis. Figure 9 shows the spectrum of evolved gases at the reaction times in which the main decomposition processes took place (according to Section 3.1). The main detected evolved species from the combustion of stems and leaves were: $\mathrm{CO}_{2}[2349$ $\left.\mathrm{cm}^{-1} ; \mathrm{v}(\mathrm{O}=\mathrm{C}=\mathrm{O})\right], \mathrm{CO}\left[2138 \mathrm{~cm}^{-1} ; \mathrm{v}(\mathrm{C} \cdots \mathrm{O})\right]$ and $\mathrm{H}_{2} \mathrm{O}\left[3900-3400 \mathrm{~cm}^{-1} ; \mathrm{v}(\mathrm{H}-\mathrm{O})\right] . \mathrm{CH}_{4}$ was almost inappreciable $\left(3019 \mathrm{~cm}^{-}\right.$ $\left.{ }^{1}\right)$ and the vibration of the groups $\mathrm{C}=\mathrm{O}\left(1740-1720 \mathrm{~cm}^{-1}\right)$ and $\mathrm{C}-\mathrm{O}-\mathrm{C}\left(1270-1060 \mathrm{~cm}^{-1}\right)$ were also clearly identified in all the spectrums. As it can be seen, the peaks corresponding to $\mathrm{CO}$ and $\mathrm{CO}_{2}$ evolve with bigger intensity with the increasing time in both leaves and stems cases indicating the enhancement of combustion reactions.

Overall, the obtained kinetic parameters for the two studied residues presented similar values, also comparable to those for other residues produced in the same period of the year (i.e. rice straw [22]). This fact enables the possibility of mixing them to perform their joint valorisation, avoiding high separation costs and promoting the use of renewable sources. This information will be used for the design of a Spouted Bed Reactor that will carry out the thermo-chemical reactions for the energy valorisation of the described waste. 


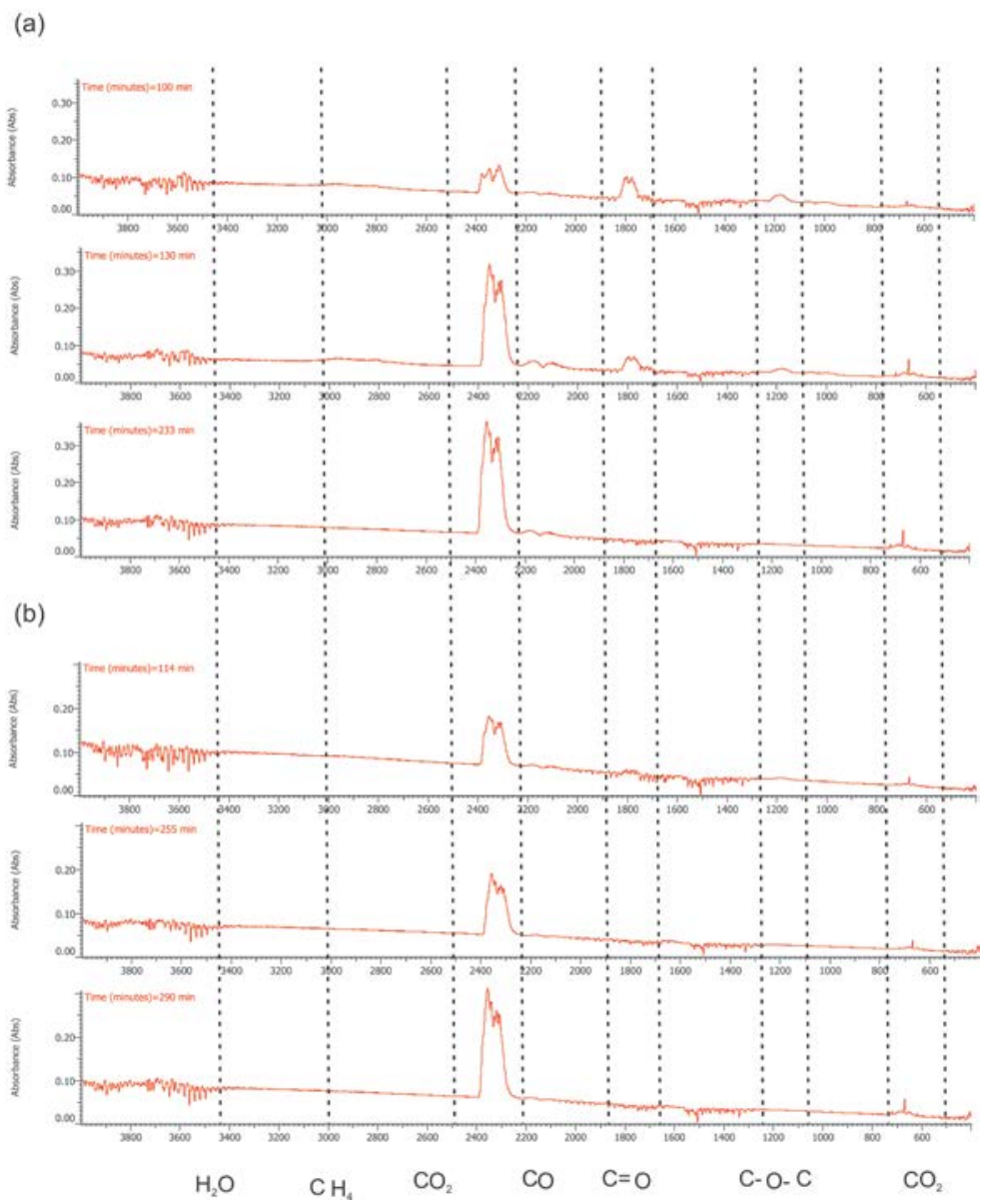

Figure 9. FT-IR spectra of stems (a) and leaves (b) at the time of the main decomposition processes

\section{Conclusions}

The residues from the harvest of persimmon are available biomass that can be used as renewable feedstock for energy recovery purposes. The assessment of the kinetics of the thermo-oxidative chemical reactions permitted to obtain the initial parameters to help design the Spouted Bed Reactor and it is envisaged that they will be used in a computer simulation software to achieve a better understanding of the process to obtain the optimum operational parameters.

Stems and leaves of persimmon were found to be highly heterogeneous and, thanks to their similar composition, both presented similar decomposition profiles yielding similar evolved gases. Moreover, the calculated kinetic parameters were found to be comparable to other lignocellulosic materials describing the thermo-oxidative reactions, proving the feasibility of their energetic valorisation also mixed with other residues, as for example rice straw, promoting its use as renewable resources with economic associated benefits .

\section{Acknowledgements}

This research did not receive any specific grant from funding agencies in the public, commercial, or not-for-profit sectors. 
C. Moliner, K. Aguilar, B. Bosio, E. Arato, A. Ribes-Greus. Thermo-oxidative characterisation of the residues from persimmon harvest for its use in energy recovery processes. Fuel Processing Technology 2016; 152:421-429

\section{References}

[1] Lim J.S., Manan Z. A., Rafidah S., Alwi W., Hashim H., A review on utilisation of biomass from rice industry as a source of renewable energy. Renewable and Sustainable Energy Reviews 16 (2012) 3084-3094.

[2] Martínez-Calvo J., Naval M. M., Badenes M. L., Llácer G. Programa de mejora genética del caqui en el Instituto Valenciano de Investigaciones Agrarias. Vida rural 354 (2012) 14-18. ISSN 1133-8938.

[3] Tanger P., Field L., Jahn C., DeFoort M., Leach J.E. Biomass for thermo-chemical conversion: targets and challenges. Front. Plant Sci. 4 (2013) 218.

[4] Epstein N., Grace J.R., Spouted and Spout-fluid beds. Fundamentals and applications. Ed. Cambridge University Press (2011).

[5] McKendry P. Energy production of biomass (part 1): overview of biomass. Bioresource Technology 83 (2002) 37-46.

[6] White J. E., Catallo W.J., Legendre B.L. Biomass pyrolysis kinetics: a comparative critical review with relevant agricultural residue case studies. Journal of Analytical and Applied Pyrolysis 91 (2011) 1-33.

[7] Pantoja-Castro M.A., Gonzalez-Rodriguez H. Study by infrared spectroscopy and thermogravimetric analysis of tannins and tannic acid. Rev. Latinoamer. Chim.39 (2011) 3.

[8] Channiwala, S.A., Parikh P.P., A unified correlation for estimating the HHV of solid, liquid and gaseous fuels. Fuel 81 (8) (2002) 1051-1063.

[9] Amutio M., Lopez G., Aguado R., Artetxe M., Bilbao J., Olazar M. Kinetic study of lignocellulosic biomass oxidative pyrolysis. Fuel 95 (2012) 305-311.

[10] Vassilev S.V., Baxter D., Andersen L.K.., Vassileva C.G., Morgan T.J. An overview of the organic and inorganic phase composition of biomass. Fuel 94 (2012) 1-33.

[11] Badia JD, Santonja-Blasco L, Martinez-Felipe A, Ribes-Greus A. A methodology to assess the energetic valorization of bio-based polymers from the packaging industry: pyrolysis of reprocessed polylactide. Bioresour Technol 111 (2012) 468-475.

[12] Badia JD, Martinez-Felipe A, Santonja-Blasco L, Ribes-Greus A. Thermal and thermo-oxidative stability of reprocessed poly(ethylene terphthalate). J Anal Appl Pyrol 99 (2013) 191-202.

[13] Flynn J.H., Wall L.A., A quick, direct method for the determination of activation energy from thermogravimetric data. Journal of Polymer Science 4 (1966) 323-342.

[14] Akahira T., Sunose Trans.Joint Convention of Four Electrical Institutes, Paper N.246, Research Report/Chiba Institute of Technology. Scientific Technology 16 (1971) 22-31.

[15] Vyazovkin S., Advanced isoconversional method, Journal of thermal analysis 49 (1997) 1493-1499. 
[16] Senum G.I., Yang R.T. Rational approximations of the integral of the Arrhenius function. Journal of Thermal Analysis and Calorimetry, 11 (1977) 445-447.

[17] Santos K.G., Lobato F.S., Lira T.S, Murata V.V., Barrozo M.A.S. Sensitivity analysis applied to independent parallel reaction model for pyrolysis bagasse. Chem Eng. Res. Des. 90 (2012) 1989-1996.

[18] Damartzis T., Vamvuka D., Sfakiotakis S., Zabaniotou A. Thermal degradation studies and kinetic modeling of cardoon (Cynara cardunculus) pyrolysis using thermogravimetric analysis (TGA). Bioresource Technology 102 (2011) 6230-6238.

[19] Gotor F.J,.Criado J.M, Malek J., Koga N., Kinetic analysis of solid-state reactions: the universatility of master plots for analysing isothermal and non-isothermal experiments. Journal of Physical Chemistry A 104 (2000) 10777-10782.

[20] Khawam A. , Flanagan D.R. Solid-State kinetic models: basics and mathematical fundamentals. J.Phys.Chem.B 110 (2006) $35,17315-17328$.

[21]Coats A.W., Redfern J.P., Kinetic parameters from thermogravimetric data. Nature 201 (1964) 68-69.

[22] Moliner C., Bosio B., Arato E., Ribes A. Thermal and thermo-oxidative characterisation of rice straw for its use in energy valorisation processes. Fuel 180 (2016) 71-79 
C. Moliner, K. Aguilar, B. Bosio, E. Arato, A. Ribes-Greus. Thermo-oxidative characterisation of the residues from persimmon harvest for its use in energy recovery processes. Fuel Processing Technology 2016; 152:421-429

\section{Annex. Open-access policies}

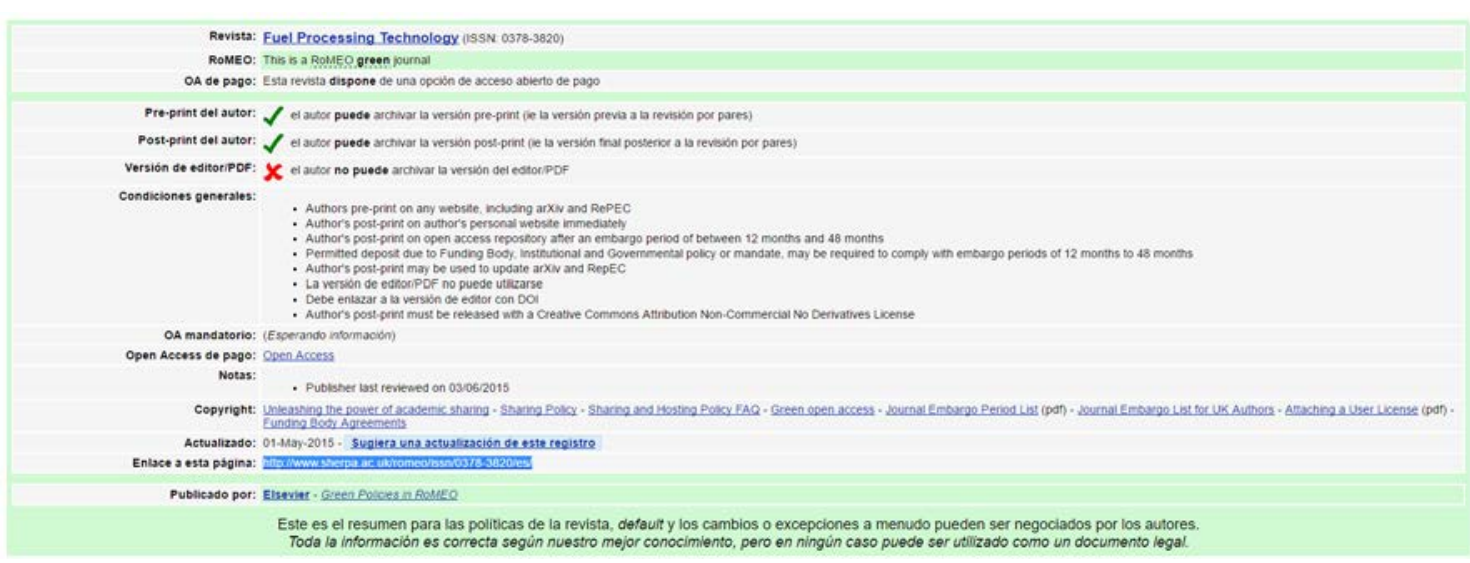

